Pacific Journal of Mathematics

CERTAIN GENERALIZED HYPERGEOMETRIC IDENTITIES
OF THE ROGERS-RAMANUJAN TYPE. II 


\title{
CERTAIN GENERALIZED HYPERGEOMETRIC IDENTITIES OF THE ROGERS-RAMANUJAN TYPE (II)
}

\author{
V. N. SINGH
}

1. Introduction. Nearly two years ago, Alder [1] established the following generalizations of the well-known Rogers-Ramanujan identities:

$$
\begin{aligned}
& \prod_{n=1}^{\infty} \frac{\left(1-x^{(2 M+1) n-M}\right)\left(1-x^{(2 M+1) n-(M+1)}\right)\left(1-x^{(2 M+1) n}\right)}{\left(1-x^{n}\right)}=\sum_{t=0}^{\infty} \frac{G_{M, t}(x)}{(x)_{t}}, \\
& \prod_{n=1}^{\infty} \frac{\left(1-x^{(2 M+1) n-1}\right)\left(1-x^{(2 M+1) n-2 M}\right)\left(1-x^{(2 M+1) n}\right)}{\left(1-x^{n}\right)}=\sum_{t=0}^{\infty} x^{t} \frac{G_{M, t}(x)}{(x)_{t}},
\end{aligned}
$$

where $G_{M, t}(x)$ are polynomials which reduce to $x^{t^{2}}$ for $M=2$ and

$$
(x)_{t}=(1-x)\left(1-x^{2}\right) \cdots\left(1-x^{t}\right), \quad(x)_{0}=1 .
$$

In a recent paper [6] I gave a simple alternative proof of (1) and (2). We used the result

$$
\begin{aligned}
1+\sum_{s=1}^{\infty}(-1)^{s} k k^{M s} & x^{\frac{1}{2} s\{(2 M+1) s-1\}}\left(1-k x^{2 s}\right) \frac{(k x)_{s-1}}{(x)_{s}} \\
= & \prod_{n=1}^{\infty}\left(1-k x^{n}\right) \sum_{t=0}^{\infty} \frac{k^{t} G_{M, t}(x)}{(x)_{t}}, \quad M=2,3, \cdots
\end{aligned}
$$

Alder in his paper states that identities involving the generating function for the number of partitions into parts not congruent to 0 , $\pm(M-r)(\bmod 2 M+1)$, where $0 \leqq r \leqq M-1$, can be obtained by his method and indicates the result for $r=1$.

In the present paper I give a simple method of obtaining the $M$ identities for each modulus $(2 M+1)$. In $\S 4$ identities for which $r \geqq \frac{1}{2} M$ have been deduced and in $\S 5$ those for which $r \leqq \frac{1}{2} M$ have been obtained for any $r$ such that $0 \leqq r \leqq M-1$. The identities given in $\S 5$ have not been mentioned by Alder. As a corollary, an interesting identity between two infinite series is given.

2. Notations. Assuming $|x|<1$, let

$$
\begin{aligned}
(\alpha)_{n} & \equiv(\alpha)_{x, n}=(1-\alpha)(1-\alpha x) \cdots\left(1-\alpha x^{n-1}\right), \quad(\alpha)_{0}=1, \\
(\alpha)_{-n} & =(-1)^{n} x^{\frac{1}{2} n(n+1)} / \alpha^{n}(x / \alpha)_{n}, \\
x_{n} & =1+x+x^{2}+\cdots+x^{n-1} .
\end{aligned}
$$

Received February 9, 1357. 


$$
P_{m, t}(x) \equiv x^{\frac{1}{2}(t+1-m) t} \frac{(x)_{m}}{(x)_{t}(x)_{m-t+1}}\left(1-x^{m-2 t+1}\right)
$$

and let

$$
\phi\left(M, x^{r}\right)=1+\sum_{s=1}^{\infty}(-1)^{s} x^{M r s} x^{\frac{1}{2} s\{(2 M+1) s-1\}}\left(1-x^{2 s+r}\right)\left(x^{s+1}\right)_{r-1},
$$

so that (3) can be written as

$$
\phi\left(M, x^{r}\right)=\prod_{n=1}^{\infty}\left(1-x^{n}\right) \sum_{t=0}^{\infty} \frac{x^{r t} G_{M, t}(x)}{(x)_{t}} .
$$

3. The polynominals $\boldsymbol{u}_{n}(\boldsymbol{x})$. Before proceeding to deduce the generalized identities, we first give a few properties of a sequence of polynomials with the help of an operator. These we will need in later sections. Let us define a sequence $\left\{u_{n}(x)\right\}$ of polynomials by the relations

$$
\begin{aligned}
& u_{0}(x)=0 \\
& u_{n}(x)=u_{n-1}(x)+x^{n-1} x_{n}, \\
& n \geqq 1 .
\end{aligned}
$$

Let $\mathscr{R}$ be an operator which replaces $x_{m}$ by $u_{m}(x)$ in any $u_{n}(x)$, that is,

$$
\mathscr{R} u_{n}(x)=\mathscr{R} u_{n-1}(x)+x^{n-1} u_{n}(x) \text {. }
$$

Also

$$
\mathscr{R}^{n} u_{m}(x)=\mathscr{R}^{n-1}\left\{\mathscr{R} u_{m}(x)\right\}
$$

Then we have

$$
(\alpha)_{n}=1-\alpha x_{n}+\sum_{s=2}^{n}(-\alpha)^{s} x^{\frac{1}{2} s(s-1)} \mathscr{R}^{s-2} u_{n-s+1}(x) .
$$

As can be easily shown

$$
\mathscr{R}^{s-2} u_{n-s+1}(x)=\frac{(x)_{n}}{(x)_{s}(x)_{n-s}} .
$$

The above polynomials (8) have also recently occurred in a paper by Carlitz [3].

Comparing the coefficients of $\alpha^{s-1}$ in

$$
(\alpha)_{n}=(-1)^{n} \alpha^{n} x^{\frac{1}{2} n(n-1)}\left(1 / \alpha x^{n-1}\right)_{n},
$$

we get the relation

$$
\mathscr{R}^{s-3} u_{n-s+2}(x)=\mathscr{R}^{n-s-1} u_{s}(x), \quad s=1, \cdots,(n+1) .
$$

We can thus write (7) as 


$$
(\alpha)_{n}=\sum_{s=0}^{n}(-\alpha)^{s} x^{\frac{1}{2} s(s-1)} \mathscr{R}^{s-2} u_{n-s+1}(x),
$$

where negative indices of $\mathscr{R}$ are defined by (10). Again comparing the coefficients of $\alpha^{s}$ in

$$
\left(\alpha / x^{n-1}\right)_{x, n}=(\alpha)_{1 / x, n},
$$

we get with the help of (11),

$$
\mathscr{R}^{s-2} u_{n-s+1}(x)=x^{s(n-s)} \mathscr{R}^{s-2} u_{n-s+1}\left(x^{-1}\right) .
$$

In particular

$$
u_{n}(x)=x^{2 n-2} u_{n}\left(x^{-1}\right) .
$$

The following values of $\mathscr{R}^{m} u_{n}(x)$ will also be required:

$$
\begin{aligned}
& \quad \mathscr{R}^{n-3} u_{2}(x)=x_{n}, \\
& u_{1}(x)=1 \\
& u_{3}(x)=1+x+2 x^{2}+x^{3}+x^{4} \\
& u_{4}(x)=1+x+2 x^{2}+2 x^{3}+2 x^{4}+x^{5}+x^{6}=\mathscr{R} u_{3}(x) .
\end{aligned}
$$

4. Now we proceed to deduce identities involving the generating function for the number of partitions into parts not congruent to 0 , $\pm(M-r)(\bmod 2 M+1)$. From $(11)$, we have

$$
\begin{aligned}
& \left(x^{n-r+1}\right)_{2 r-1}\left(1-x^{2 n}\right) \\
& =\left[1+\sum_{s=1}^{2 r-2}\left\{\left(-x^{n-r+1}\right)^{s} x^{\frac{1}{2} s(s-1)} \mathscr{R}^{s-2} u_{2 r-s}(x)\right\}-x^{(2 r-1) n}\right]\left(1-x^{2 n}\right),
\end{aligned}
$$

whence

$$
\begin{aligned}
1+ & x^{(2 r+1) n} \\
= & {\left[x^{2 n}+x^{(2 r-1) n}-\left\{\sum_{s=1}^{2 r-2} x^{n s}(-1)^{s} x^{\frac{1}{2} s(s+1)-r s} \mathscr{R}^{s-2} u_{2 r-s}(x)\right\}\left(1-x^{2 n}\right)\right] } \\
& +\left(1-x^{2 n}\right)\left(x^{n-r+1}\right)_{2 r-1} .
\end{aligned}
$$

And since, because of (8) or (10), the terms equidistant from the two ends in the sum on the right of (14) have equal coefficients of powers of $x^{n}$, the expression in square brackets can be written as

$$
\sum_{t=1}^{r}(-1)^{t-1} x^{t n}\left\{1+x^{(2 r-2 t+1) n}\right\} U_{r, t}(x)
$$

where

$$
\begin{array}{rlrl}
U_{r, t}(x) & =x^{\frac{1}{2} t(t+1)-t r} \mathscr{R}^{t-2} u_{2 r-t}(x)-x^{\frac{1}{2}(t-2)(t-1)-(t-2) r} \mathscr{R}^{t-1} u_{2 r-t+2}(x) \\
& =P_{2 r, t}(x), & \text { using (4) and (8). }
\end{array}
$$


The polynomials $U_{r, t}(x)$ may be called "reciprocal" since they are such that the terms equidistant from the two ends have equal coefficients. Taking $n=0$ in (14) we see that

$$
\sum_{t=1}^{r}(-1)^{t-1} U_{r, t}(x)=1 .
$$

Also, with the help of (12), we have

$$
U_{r, t}(x)=U_{r, t}\left(x^{-1}\right) .
$$

Now from (15)

$$
\begin{aligned}
& \sum_{n=-\infty}^{\infty}(-1)^{n} x^{\frac{1}{2} n\{(2 M+1) n+2 r+1\}} \\
& =1+\sum_{n=1}^{\infty} \frac{(-1)^{n} x^{\frac{1}{2} n\{(2 M+1) n-1\}}}{x^{r n}}\left\{1+x^{(2 r+1) n}\right\} \\
& =1+\sum_{t=1}^{r}(-1)^{t-1} U_{r, t}(x) \sum_{n=1}^{\infty} \frac{(-1)^{n} x^{\frac{1}{2} n\{(2 M+1) n-1\}}}{x^{(r-t) n}}\left\{1+x^{(2 r-2 t+1) n}\right\} \\
& \quad+\sum_{n=1}^{\infty} \frac{(-1)^{n} x^{\frac{1}{2} n\{(2 M+1) n-1\}}}{x^{r n}}\left(1-x^{2 n}\right)\left(x^{n-r+1}\right)_{2 r-1} .
\end{aligned}
$$

For $n=s+r$, the last series on the right-hand side of (19) becomes

$$
(-1)^{r} x^{M r^{2}-\frac{1}{2} r(r+1)} \phi\left(M, x^{2 r}\right)
$$

since the first $(r-1)$ terms of the series vanish because of the factor $\left(x^{n-r+1}\right)_{2 r-1}$. Then using (17) and writing

$$
F(M, r)=\sum_{n=-\infty}^{\infty}(-1)^{n} x^{\frac{1}{2} n\{(2 M+1) n+2 r+1\}}
$$

we obtain for (19) the form

$$
F(M, r)=\sum_{t=1}^{r}(-1)^{t-1} U_{r, t}(x) F(M, r-t)+(-1)^{r} x^{M r^{2}-\frac{1}{2} r(r+1)} \phi\left(M, x^{2 r}\right) .
$$

Thus, using Jacobi's classical identity

$$
\sum_{n=-\infty}^{\infty}(-1)^{n} x^{n^{2}} z^{n}=\prod_{n=1}^{\infty}\left(1-x^{2 n-1} z\right)\left(1-x^{2 n-1} / z\right)\left(1-x^{2 n}\right)
$$

to express the infinite series in (20) as infinite products, we could find for any given $r$, such that $0 \leqq r \leqq M-1$, an expression for the generating function for the number of partitions into parts not congruent to 0 , $\pm(M-r)(\bmod 2 M+1)$ in terms of generating functions for the number of partitions into parts not congruent to $0, \pm(M-s)(\bmod 2 M+1)$, 
$(s=0,1,2, \cdots, r-1)$. Since $F(M, 0)=\phi(M, 1)$, the $F$-series can be successively expressed in terms of $\phi$-series and, with the help of (6), we get

\section{TheOREM 1.}

$$
\prod_{n=1}^{\infty} \frac{\left(1-x^{(2 M+1) n-(M-r)}\right)\left(1-x^{(2 M+1) n-(M+r+1)}\right)\left(1-x^{(2 M+1) n}\right)}{\left(1-x^{n}\right)}=\sum_{t=0}^{\infty} \frac{A,(x, t) G_{M, t}(x)}{(x)_{t}}
$$

where

$$
A_{r}(x, t)=\sum_{s=0}^{r}(-1)^{s} x^{M s^{2}-\frac{1}{2} s(s+1)+2 s t} U_{r, s+1}^{\prime}(x) .
$$

The polynomials $U^{\prime}(x)$ are of the "reciprocal" kind, with

$$
\begin{aligned}
& U_{r, r+1}^{\prime}(x)=1 \\
& U_{r, s+1}^{\prime}(x)=\sum_{m=1}^{r-s}(-1)^{m-1} U_{r, m}(x) U_{r-m, s+1}^{\prime}(x), \quad s \neq r .
\end{aligned}
$$

so that

$$
U_{r, 1}^{\prime}(x)=1
$$

and

$$
U_{r, m}^{\prime}(x)=U_{r, m}^{\prime}\left(x^{-1}\right), \quad \text { because of }(18) .
$$

As an example of Theorem 1 , taking the case $r=1$, we have

$$
1+x^{3 n}=x^{n}\left(1+x^{n}\right)+\left(1-x^{n}\right)\left(1-x^{2 n}\right) .
$$

Therefore

$$
\sum_{n=-\infty}^{\infty}(-1)^{n} x^{\frac{1}{2} n\{(2 M+1) n+3\}}=\phi(M, 1)-x^{M-1} \phi\left(M, x^{2}\right)
$$

which is equivalent to equation (23) of Alder [1].

From (23), using (21) and (6), we get the identity

$$
\begin{array}{r}
\prod_{n=1}^{\infty} \frac{\left(1-x^{(2 M+1) n-(M-1)}\right)\left(1-x^{(2 M+1) n-(M+2)}\right)\left(1-x^{(2 M+1) n}\right)}{\left(1-x^{n}\right)} \\
=\sum_{t=0}^{\infty} \frac{\left(1-x^{M+2 t-1}\right)}{(x)_{t}} G_{M, t}(x) .
\end{array}
$$

For $r=2$,

$$
\begin{aligned}
\prod_{n=1}^{\infty}\left(1-x^{(2 M+1) n-(M-2)}\right)\left(1-x^{(2 M+1) n-(M+3)}\right)\left(1-x^{(2 M+1) n}\right) & \left(1-x^{n}\right) \\
= & \sum_{t=1}^{\infty} \frac{\left\{1-U_{2,2}^{\prime}(x) x^{M+2 t-1}+x^{4 \mathbf{M}+4 t-3}\right\}}{(x)_{t}} G_{M, t}(x),
\end{aligned}
$$


where

$$
U_{2,2}^{\prime}(x)=x^{-1}+1+x .
$$

Similarly for $r=3$ we get

$$
\begin{aligned}
& U_{3,2}^{\prime}(x)=x^{-2}+x^{-1}+2+x+x^{2} \\
& U_{3,3}^{\prime}(x)=x^{-2}+x^{-1}+1+x+x^{2},
\end{aligned}
$$

and so on for any $r$ such that $0 \leqq r \leqq M-1$.

5. In this section identities involving the generating function for the number of partitions into parts not congruent to $0, \pm r(\bmod 2 M+1)$ are obtained.

From (11) we have

$$
\begin{aligned}
& \left(x^{n-r+2}\right)_{2 r-2}\left(1-x^{2 n+1}\right) \\
& \quad=\left[1+\left\{\sum_{s=1}^{2 r-3}\left(-x^{n-r+2}\right)^{s} x^{\frac{1}{2} s(s-1)} \mathscr{R}^{s-2} u_{2 r-s-1}(x)\right\}+x^{(2 n+1)(r-1)}\right]\left(1-x^{2 n+1}\right),
\end{aligned}
$$

whence

$$
1-x^{(2 n+1) r}
$$

$$
\begin{gathered}
=\left[x^{2 n+1}-x^{(2 n+1)(r-1)}-\left\{\sum_{s=1}^{2 r-3} x^{n s}(-1)^{s} x^{\frac{1}{2} s(s+3)-r s} \mathscr{R}^{s-2} u_{2 r-s-1}(x)\right\}\left(1-x^{2 n+1}\right)\right] \\
+\left(1-x^{2 n+1}\right)\left(x^{n-r+2}\right)_{2 r-2} .
\end{gathered}
$$

In the expression in square brackets in (26), the terms containing $x^{n r}$ cancel and the other terms can again be grouped in pairs to give

$$
1-x^{(2 n+1) r}=\sum_{t=1}^{r-1}(-1)^{t-1} V_{r, t}(x) x^{t n}\left\{1-x^{(2 n+1)(r-t)}\right\}+\left(1-x^{2 n+1}\right)\left(x^{n-r+2}\right)_{2 r-2},
$$

where

$$
\begin{aligned}
V_{r, t}(x) & =x^{\frac{1}{2} t(t+3)-r t} \mathscr{R}^{t-2} u_{2 r-t-1}(x)-x^{\frac{1}{2} t(t-1)-r(t-2)} \mathscr{R}^{t-4} u_{2 r-t+1}(x) \\
& =x^{\frac{1}{2} t} P_{2 r-1, t}(x) .
\end{aligned}
$$

The polynomials $V(x)$ are less symmetric than $U(x)$. In particular, corresponding to (17) and (18), they satisfy the relations

$$
\sum_{t=1}^{r-1}(-1)^{t-1} V_{r, t}(x) x_{r-t}=x_{r},
$$

and

$$
V_{r, t}(x)=x^{t} V_{r, t}\left(x^{-1}\right)
$$

Now 


$$
\begin{aligned}
& \sum_{n=-\infty}^{\infty}(-1)^{n} x^{\frac{1}{2} n\{(2 M+1)(n+1)\}-r n} \\
&=\sum_{n=0}^{\infty} \frac{(-1)^{n} x^{\frac{1}{2} n^{2}(2 M+1)+\left(M-\frac{1}{2}\right) n}}{x^{(r-1) n}}\left\{1-x^{(2 n+1) r}\right\} .
\end{aligned}
$$

Denoting the left-hand side of the last equation by $\psi(M, r)$ and using (27) and (5), we get, after slight simplification,

$$
\psi(M, r)=\sum_{t=1}^{r-1}(-1)^{t-1} \psi(M, r-t) V_{r, t}(x)+(-1)^{r-1} x^{\frac{1}{2}(2 M-1) r(r-1)} \phi\left(M, x^{2 r-1}\right)
$$

Using (21), the generating function for the number of partitions into parts not congruent to $0, \pm r(\bmod 2 M+1)$ can now be expressed in terms of the generating function for the number of partitions into parts not congruent to $0, \pm s(\bmod 2 M+1),(s=1,2, \cdots, r-1)$. Thus, we finally have

\section{THEOREM 2.}

$$
\prod_{n=1}^{\infty} \frac{\left(1-x^{(2 M+1) n-r}\right)\left(1-x^{(2 M+1) n-(2 M+1-r)}\right)\left(1-x^{(2 M+1) n}\right)}{\left(1-x^{n}\right)}=\sum_{t=0}^{\infty} \frac{B_{r}(x, t) G_{M, t}(x)}{(x)_{t}}
$$

where

$$
B_{r}(x, t)=\sum_{s=1}^{r}(-1)^{s-1} x^{\frac{1}{2}(2 M-1) s(s-1)+(2 s-1) t} V_{r, s}^{\prime}(x),
$$

and $V_{r, s}^{\prime}(x)$ are polynomials with

$$
\begin{aligned}
& V_{r, r}^{\prime}(x)=1 \\
& V_{r, s}^{\prime}(x)=\sum_{m=1}^{r-s}(-1)^{m-1} V_{r, m}(x) V_{r-m, s}^{\prime}(x),
\end{aligned}
$$

$s \neq r$,

so that

$$
V_{r, 1}^{\prime}(x)=x_{r}
$$

and

$$
V_{r, t}^{\prime}(x)=x^{r-t} V_{r, t}^{\prime}\left(x^{-1}\right) \text {. }
$$

As an illustration, for $r=2$ in Theorem 2, we have

$$
1-x^{4 n+2}=x^{n}(1+x)\left(1-x^{2 n+1}\right)+\left(1-x^{2 n+1}\right)\left(1-x^{n}\right)\left(1-x^{n+1}\right) .
$$

Therefore

$$
\sum_{n=-\infty}^{\infty}(-1)^{n} x^{\frac{1}{2} n^{2}(2 M+1)+\left(M-\frac{3}{2}\right) n}=(1+x) \phi(M, x)-x^{2 M-1} \phi\left(M, x^{3}\right),
$$

which gives us the identity 


$$
\begin{aligned}
\prod_{n=1}^{\infty}\left(1-x^{(2 M+1) n-2}\right)(1- & \left.x^{(2 M+1) n-(2 M-1)}\right)\left(1-x^{(2 M+1) n}\right) \\
& \left(1-x^{n}\right) \\
= & \sum_{t=0}^{\infty} \frac{\left\{(1+x) x^{t}-x^{2 M+3 t-1}\right\}}{(x)_{t}} G_{M, t}(x) .
\end{aligned}
$$

CoRollary. If $r$ is replaced by $M-r$ in Theorem 2 then the lefthand sides of (22) and (32) become the same and we have

$$
\begin{aligned}
\sum_{t=0}^{\infty} \frac{A_{r}(x, t) G_{M, t}(x)}{(x)_{t}}=\sum_{t=0}^{\infty} \frac{B_{M-r}(x, t) G_{M, t}(x)}{(x)_{t}}, \\
\quad r=0,1, \cdots, M-1, M=2,3, \cdots .
\end{aligned}
$$

For $M=2$ and $r=0$ and 1 we get respectively the relations

$$
\begin{aligned}
& \sum_{t=0}^{\infty} \frac{x^{t^{2}}}{(x)_{t}}=\sum_{t=0}^{\infty} \frac{\left\{(1+x) x^{t}-x^{3(t+1)}\right\}}{(x)_{t}} x^{t^{2}} \\
& \sum_{t=0}^{\infty} \frac{\left(1-x^{2 t+1}\right)}{(x)_{t}} x^{t^{2}}=\sum_{t=0}^{\infty} \frac{x^{t+t^{2}}}{(x)_{t}}
\end{aligned}
$$

the truth of which can easily be verified.

Some time ago, Slater ([4] and [5]) gave a very large number of identities of the Rogers-Ramanujan type using Bailey's summation theorem [2] for a well-poised ${ }_{6} \Psi_{6}$. It is interesting to note that, as special cases of our identities, we get some of those given by Slater, differing only in form as can be easily verified. To mention an example, let us take equation (90) of Slater [5]:

$$
\prod_{n=1}^{\infty} \frac{\left(1-x^{27 n-3}\right)\left(1-x^{27 n-24}\right)\left(1-x^{27 n}\right)}{\left(1-x^{n}\right)}=\sum_{t=0}^{\infty} \frac{\left(x^{3}\right)_{x^{3}, x^{t(t+3)}}}{(x)_{t}(x)_{2 t+2}}
$$

If we put $M=13, r=3$ in Theorem 2 , we obtain another series for the product on the left of (35). I propose to study the equivalence of identities (22) and (32) above and those of Slater in a subsequent paper, as also identities involving products in which the powers increase by $2 M$.

I would like to express my gratitude to Dr. R. P. Agarwal for suggesting the present work and for his kind help in the preparation of this paper.

\section{REFERENCES}

1. H. L. Alder, Generalizations of the Rogers-Ramanujan identities, Pacific J. Math., 4 (1954), 161-168.

2. W. N. Bailey, Series of the hypergeometric type which are infinite in both directions, Quart. J. Math., 7 (1936), 105-115.

3. L. Carlitz, The expansion of certain products, Proc. Amer, Math, Soc., 7 (1956), 558564. 
4. L. J. Slater, A new proof of Rogers's transformation of infinite series, Proc. London Math. Soc. (2), 53 (1951), 460-475.

5. - Further identites of the Rogers-Ramanujan type, Proc. London Math. Soc. (2), 54 (1952), 147-167.

6. V. N. Singh, Certain generalized hypergeometric identities of the Rogers-Ramanujan type Pacific J. Math. 7 (1957), 1011-1014.

Corrigenda. In [6] the following corrections may be noted:

p. 1011. The series for $T_{n, m}$ runs up to

$$
t_{n}=\left[\frac{M-n-1}{M-n} t_{n-1}\right] \text {. }
$$

p. 1012. In the line immediately preceding (3.3), $a_{2 ณ n-1}$ should be $a_{2 M+1}$.

In the right hand side of $(3.4)$ a factor $(k n ; t)$ should be inserted in the denominator of the outer series.

p. 1014. In the right hand side of the last identity of the paper, we should have $I$ instead of $\pi$.

UNIVERSITY OF LUCKNOW

LUCKNOW, INDIA 



\title{
PACIFIC JOURNAL OF MATHEMATICS
}

\section{EDITORS}

H. L. RoYden

Stanford University

Stanford, California

\section{R. A. Beaumont}

University of Washington

Seattle 5 , Washington
A. L. Whiteman

University of Southern California

Los Angeles 7, California

E. G. Straus

University of California

Los Angeles 24, California

\section{ASSOCIATE EDITORS}

\author{
E. F. BECKENBACH \\ C. E. BURGESS \\ M. HALL \\ E. HEWITT
}
A. HORN
V. GANAPATHY IYER
R. D. JAMES
M. S. KNEBELMAN

L. NACHBIN

I. NIVEN

T. G. OSTROM

M. M. SCHIFFER
G. SZEKERES

F. WOLF

K. YOSIDA

\section{SUPPORTING INSTITUTIONS}

\author{
UNIVERSITY OF BRITISH COLUMBIA \\ CALIFORNIA INSTITUTE OF TECHNOLOGY \\ UNIVERSITY OF CALIFORNIA \\ MONTANA STATE UNIVERSITY \\ UNIVERSITY OF NEVADA \\ OREGON STATE COLLEGE \\ UNIVERSITY OF OREGON \\ UNIVERSITY OF SOUTHERN CALIFORNIA
}

Mathematical papers intended for publication in the Pacific Journal of Mathematics should be typewritten (double spaced), and the author should keep a complete copy. Manuscripts may be sent to any of the editors. All other communications to the editors should be addressed to the managing editor, E. G. Straus at the University of California, Los Angeles 24, California.

50 reprints per author of each article are furnished free of charge; additional copies may be obtained at cost in multiples of 50 .

The Pacific Journal of Mathematics is published quarterly, in March, June, September, and December. The price per volume (4 numbers) is $\$ 12.00$; single issues, $\$ 3.50$. Back numbers are available. Special price to individual faculty members of supporting institutions and to individual members of the American Mathematical Society: $\$ 4.00$ per volume; single issues, $\$ 1.25$.

Subscriptions, orders for back numbers, and changes of address should be sent to Pacific Journal of Mathematics, 2120 Oxford Street, Berkeley 4, California.

Printed at Kokusai Bunken Insatsusha (International Academic Printing Co., Ltd.), No. 10, 1-chome, Fujimi-cho, Chiyoda-ku, Tokyo, Japan.

PUBLISHED BY PACIFIC JOURNAL OF MATHEMATICS, A NON-PROFIT CORPORATION

The Supporting Institutions listed above contribute to the cost of publication of this Journal, but they are not owners or publishers and have no responsibility for its content or policies. 


\section{Pacific Journal of Mathematics}

\section{Vol. 7, No. 4 \\ April, 1957}

Robert Geroge Buschman, A substitution theorem for the Laplace

transformation and its generalization to transformations with

symmetric kernel .

S. D. Conte, Numerical solution of vibration problems in two space variables ...................................... 1535

Paul Dedecker, A property of differential forms in the calculus of variations ......................................... 1545

H. Delange and Heini Halberstam, A note on additive functions . . . . . . . 1551

Jerald L. Ericksen, Characteristic direction for equations of motion of non-Newtonian fluids ................................. 1557

Avner Friedman, On two theorems of Phragmén-Lindelöf for linear elliptic and parabolic differential equations of the second order ........... 1563

Ronald Kay Getoor, Additive functionals of a Markov process . . . . . . . . . 1577

U. C. Guha, $(\gamma, k)$-summability of series . . . . . . . . . . . . . . . . . . 1593

Alvin Hausner, The tauberian theorem for group algebras of vector-valued functions ...................................... 1603

Lester J. Heider, $T$-sets and abstract $(\mathrm{L})$-spaces ................. 1611

Melvin Henriksen, Some remarks on a paper of Aronszajn and

Panitchpakdi........................................ 1619

H. M. Lieberstein, On the generalized radiation problem of A. Weinstein ... 1623

Robert Osserman, On the inequality $\Delta u \geq f(u) \ldots \ldots \ldots \ldots \ldots \ldots \ldots . \ldots 1641$

Calvin R. Putnam, On semi-normal operators . . . . . . . . . . . . . . . . . . 1649

Binyamin Schwarz, Bounds for the principal frequency of the

non-homogeneous membrane and for the generalized Dirichlet integral...

Edward Silverman, Morrey's representation theorem for surfaces in metric

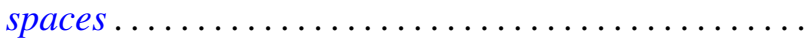

V. N. Singh, Certain generalized hypergeometric identities of the Rogers-Ramanujan type. II .

R. J. Smith, A determinant in continuous rings 1701

Drury William Wall, Sub-quasigroups of finite quasigroup 1711

Sadayuki Yamamuro, Monotone completeness of normed semi-ordered linear spaces.

C. T. Rajagopal, Simplified proofs of "Some Tauberian theorems" of Jakimovski: Addendum and corrigendum ............

N. Aronszajn and Prom Panitchpakdi, Correction to: "Extension of uniformly continuous transformations in hyperconvex metric spaces"...................................

Alfred Huber, Correction to: "The reflection principle for polyharmonic functions" 